\title{
Integrating digital Health services: the role of the government and the challenge of cost allocation
}

\author{
Frederic Vannieuwenborg, Sofie Verbrugge, Didier Colle \\ Dept. of Information Technology (INTEC) \\ Ghent University - iMinds \\ Ghent, Belgium
}

[frederic.vannieuwenborg, sofie.verbrugge, didier.colle]@intec.ugent.be

\begin{abstract}
Health, mHealth and eCare services are growing in numbers at a fast pace. This is mainly driven by technology and the societal challenges of an aging and more chronically burdened population while pressure on both human and financial resources increases. Though the adoption of these digital health services is challenging and experience difficulties. This work focusses on the main barriers that cause a 'gap' in the value network. Via case research following barriers are identified: 1) low willingness to pay, 2) unbalanced cost/benefit ratios of the actors or unfair cost allocation and 3) negative impacted business models. Furthermore the several roles of the government within the value network of digital health services are discussed and reflections and guidelines for digital health service developers are foreseen.
\end{abstract}

Keywords-component; digital health services, value network analysis, adoption barriers, role of the government

\section{INTRODUCTION}

mHealth (digital healthcare services supported by mobile devices), eHealth (ICT-supported health processes and services), eCare (eHealth services focusing on supporting care services) are all real buzz words these days. It can't be of any surprise any more that due to the societal challenges of many developed countries (an aging population combined with a care system under financial pressure) interest in mHealt, eHealth, eCare (further referred to as digital health services) has been growing significantly. Many research indicates the potential value of these kind of ICT-supported care services [1]. These added values range from gains in process and administration time [2] and more complete health context information allowing to decrease the level of anxiety of the informal care giver. All the potential value is expected to manifest in the more general form of decreased costs for care, more Quality Of Life (QOL) for the same amount of resources, or an overall increase in cost-efficiency. Meaning more QOL for the same amount of resources (e.g. time, financial resources, etc.) or the same QOL for a decreased amount of resources.

Despite of the growing interest, no major adoption of digital health services, eCare in specific, can be noticed yet. This lack of adoption has several reasons [2]. Table I provides an overview of the commonly accepted barriers for the adoption of eCare, and digital health services in general. In particular, this work wants to address the importance of the role and impact of the government and the challenge of formulating win-win cost allocations to stimulate the adoption of digital health services.

TABLE I. CURRENT BARRIERS FOR THE ADOPTION OF DIGITAL HEALTH SERVICES[2]

\begin{tabular}{|l|l|}
\hline \multicolumn{1}{|c|}{ Barrier } & \multicolumn{1}{c|}{ Description of adoption barrier } \\
\hline $\begin{array}{l}\text { A complex value } \\
\text { network for eHealth } \\
\text { services }\end{array}$ & $\begin{array}{l}\text { Integrating digital health services demands an } \\
\text { intensive collaboration of several care actors. That } \\
\text { is in contrast with the current and fragmented way } \\
\text { of the often polarized care provisioning. Often the } \\
\text { cost/benefit allocation for these actors is distorted. }\end{array}$ \\
\hline $\begin{array}{l}\text { Added value is } \\
\text { unclear, still needs } \\
\text { to be proven or is } \\
\text { hard to quantify }\end{array}$ & $\begin{array}{l}\text { Digital health services are new and innovative and } \\
\text { therefore the impact of it is not proven yet. Also } \\
\text { these services will impact more the quality of care } \\
\text { and quality of life, which is harder to measure and } \\
\text { quantify. }\end{array}$ \\
\hline $\begin{array}{l}\text { Technological } \\
\text { barriers }\end{array}$ & $\begin{array}{l}\text { There exist issues on data format standardization } \\
\text { in order to guarantee exchangeability. }\end{array}$ \\
\hline $\begin{array}{l}\text { A lack of financial } \\
\text { support/ the unclear } \\
\text { business model }\end{array}$ & $\begin{array}{l}\text { Integrating digital health services often require } \\
\text { efforts from professional care providers. Without a } \\
\text { clear financial structure or compensation, their } \\
\text { motivation to adopt and support these services is } \\
\text { and will remain low. }\end{array}$ \\
\hline $\begin{array}{l}\text { Current perceptions } \\
\text { of the involved } \\
\text { actors on the } \\
\text { healthcare system } \\
\text { affects Willingness } \\
\text { to pay }\end{array}$ & $\begin{array}{l}\text { Because of the installed care insurances, Western } \\
\text { European citizens (and other countries where } \\
\text { many healthcare costs are covered by public health } \\
\text { insurances) are not used to pay (fully) for new } \\
\text { medical devices or digital health services. }\end{array}$ \\
\hline $\begin{array}{l}\text { Privacy concerns \& } \\
\text { legal issues }\end{array}$ & $\begin{array}{l}\text { Together with the use of ICT supported care } \\
\text { services, automatically questions on data security } \\
\text { and privacy rise. }\end{array}$ \\
\hline
\end{tabular}

Last years, efforts have been in placed to tackle some these issues (e.g. standardization initiatives [3]).

\section{DigitAL HEALTH SERVICES: OFTEN AN IMPERFECT VALUE NETWORK}

Although medicine is characterized by continuous improvement and innovations, integrating digital health services into existing multi-actor care processes and systems is often a hard task. Off all the existing barriers, the unclear business model and complex value network play major roles in the cumbersome uptake. In some cases adoption is slowed down or even blocked by an actor because his current business 
model is impacted negatively when integrating the new digital health service (see example cases).

Therefore, the incapability of formulating an overall accepted and sustainable value network, is one of the main challenges to solve for boosting the adoption. A value network is the constellation of the different roles, their mutual value exchanges (e.g. monetary, tangible values e.g. goods or intangible values e.g. services) and actors involved to deliver the services to the customers [4].

The main reasons why formulating a sustainable value network and clear business model is challenging, are:

First, there is no or a low willingness to pay. Integrating digital health services often requires additional investments in software (e.g. service subscriptions) and hardware (e.g. monitoring devices, sensor gateways, etc.). In many cases there is no reimbursement provided by health insurers for these kind of services. For now, patients and care receivers often have to pay themselves for additional digital health services.

Many Western European and other developed countries have an installed healthcare system. In most cases this is (partly) paid for by public means and provides a basic healthcare insurance. On top of that, many people have additional private health insurances to extend the basic healthcare insurance. So for many health related incidents, people are covered by insurances. This given creates a gap between the perspectives on costs of healthcare: reimbursed and/or low out-of-the-pocket (OTP) costs for current care practices, versus non-reimbursed and unneglectable OTP costs for digital health services. Not surprisingly the overall willingness to pay of care receivers for digital health services is rather low for the time being.

Secondly, cost allocation is difficult. Integrating or deploying digital services often requires many actors (e.g. care receiver, home care providers, general practitioner, informal care giver, specialist, etc.) to be on board, to be involved in the value network. In these multi-actor settings, cost allocations tend to be challenging. Meaning that there is often an unbalance between cost/benefit ratios of the involved actors. For example, the actor investing the most resources does not necessarily benefits the most. Often this actor will only accept this to a certain degree. Tackling the cost allocation can result in stronger value networks.

Third, when costs are higher than the total benefits the business model is impacted in a negative way. In some cases, adopting or stimulating digital health services directly results in a negative impacted business model for one or more actors involved in the value network. For example a general practitioner who stimulates mHealth applications and monitors his patients, could in the long term experience a decreased number of visits of his patients as a result of the use of mHealth services. This would also affects his revenue streams. Thus besides their concerns about privacy protection and serviceusability [5], general practitioners could also experience a negative impact on their business model. Without official recognition of the impact of mHealth applications, it is unlikely that a financial framework will be installed to compensate the
GP for his additional effort to monitor his patients while he experiences a decreased visiting frequency.

Low willingness to pay [6], an unbalanced cost-allocation and a negative impacted business model are all potential causes why large scale adoption of digital health services could be slowed down or even be stopped by one or more actors [7].

In the next section three real-life cases are discussed that all share the common challenge, being a blocked or slow adoption of the digital health service.

\section{EXAMPLES OF CHALLENGING VALUE NETWORKS}

Following three real-life cases in a Danish and Belgian context demonstrate how the integration of digital health services into current care practices impacts the business model of one or more actors, causing them to slow down or even block the adoption of the service.

\section{A. Case "Be Well Point" a Medi kiosk in Belgian pharmacies}

The first case dates from 2014 and concerns pharma companies installing 'Point Of Care Testing' (POCT) [8] in Belgian pharmacies. This device is an automated kiosk that is able to determine several bio parameters such as BMI, blood pressure, lipid profile, HbAlc, etc. After signing a digital informed consent, patients can perform these self-tests, supervised by the pharmacists and directly send the results to the general practitioners or any other care giver of choice.

Although integrating self-test kiosks like 'Be Well Point' can be seen as positive thing to stimulate and allow people monitoring better their own health; the medical association blocked further adoption completely [9]. In their official communicated answer the medical association expresses their concerns about the reliability and quality of the tests and the procedures, as well on some privacy aspects. Focusing on the value network (see figure 1), it can be noticed that integrating a "Be Well Point" in pharmacies can lead to direct competition with general practitioners, leading to decreased visit frequencies and revenues.

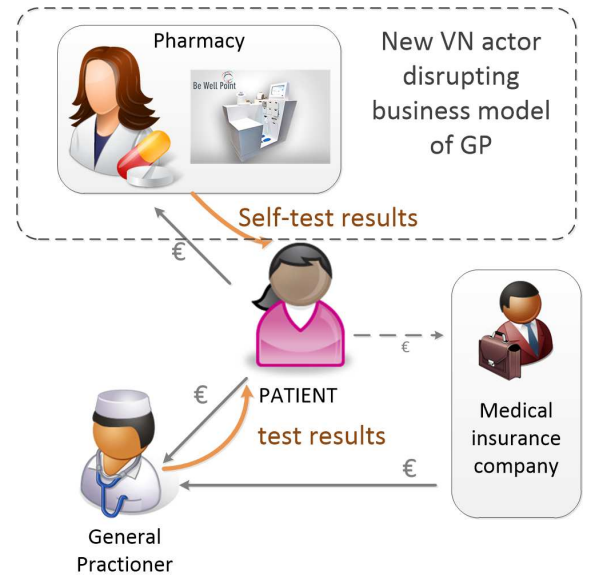

Figure 1. Simplified value network for offering a digital service, indcating the competition between the new service and the general practitioner (case: "Be Well Point") 
Although the integration of these self-test kiosks targeted bringing together patients, general practitioners or physicians in general and pharmacists and allow people monitoring important bio parameters, the final advice of medical association is that these practices are not deontological acceptable [9]. Further deployment of these medi-kiosks is not allowed.

\section{B. Case Telemonitoring heart failures}

Last decade, much research has been conducted on tele monitoring heart failure (HF) patients [10]. Closely monitoring patients suffering from HF, lowers the number of hospital readmissions and the mortality rate [10]. In most cases, it is the cardiologist or high skilled HF nurses who does the monitoring. But sometimes also the general practitioner is involved in the tele monitoring of his HF patients, since he performed the patient check-ups before integrating tele monitoring.

Just like previous case, lack of a financial framework and a potentially decreased patient visit frequency result in the medical association blocking further adoption until there are clear business models proposed and reimbursements by the government [11].

In fact, it can be noticed that in many cases integrating digital health services for which a medical actor is needed will adopt somewhat slower than would be the case without a medical actor in the value network. Sometimes it is because the physicians are reluctant because of privacy issues, medical evidence etc. In this case, it is up to the application and service developers to come up with a better product or service. But it shouldn't occur that adoption is blocked because of a lack of financial structure or business model issues.

\section{Case launching an online national platform to improve quality of care of GPS}

A third case describes the deployment of a nationwide platform, Dak-e, that extracts all required info out of the electronic health records (EHR), maintained by the general practitioners [12]. The main goal of the platform is collect data for further developing and assuring the quality of the Danish care system. The data aggregation works in background processes so no extra effort is needed, on the condition that the general practitioner uses the International Classification of Primary Care coding system (ICPC codes). For the moment, focus is on a limited set of chronic diseases.

Based on the gathered data, the platform provides insights and feedback for the general practitioners. Via national benchmarking best practices can easily be detected, learnt form and spread again. The anonymized data is also accessible for research centers.

Although this platform could have a very beneficial impact (e.g. being the detection of best practices, insights why some treatments are preferred in some parts of the country, personal feedback for the general practitioners, etc.), initial adoption of the general practitioners remained low. Also in other countries a similar challenge can be noticed (e.g. low adoption of Vitalink [13]).
Investigating the value network identifies partially the low adoption. Although the platform developers made it as a main requirement that the general practitioners shouldn't be bothered with additional administrative tasks, the main condition for the Dak-e platform to work is respecting the ICPC-coding scheme. Learning and applying the ICPC rules, will require extra efforts from the GPs. A second reason for low adoption could be the 'Big Brother' effect. Since Dak-e, a government related platform, provides insights and performs benchmarks between GPs, chances exist that this can be perceived as a controlling body.

\section{THE GOVERNMENT AS AN IMPORTANT ACTOR}

As can be noticed in the case descriptions, the cause of a low or failed adoption of digital health services is often a gap in the value network or in the business model of a key-actor.

Up to now healthcare industry players, physicians, care organizations and care receivers, expect the government and policy makers to provide the needed frameworks to operate in (e.g. legal, financial, etc.). Also an often recurring remark is the on the need for reimbursement of digital health services.

The government can fulfill several roles within the value network of digital health services. The government can impact the adoption of services and/or close the gap in the value network by fulfilling on of the following roles: regulator, healthcare payer, digital health platform provider and adoption initiator (figure 2).

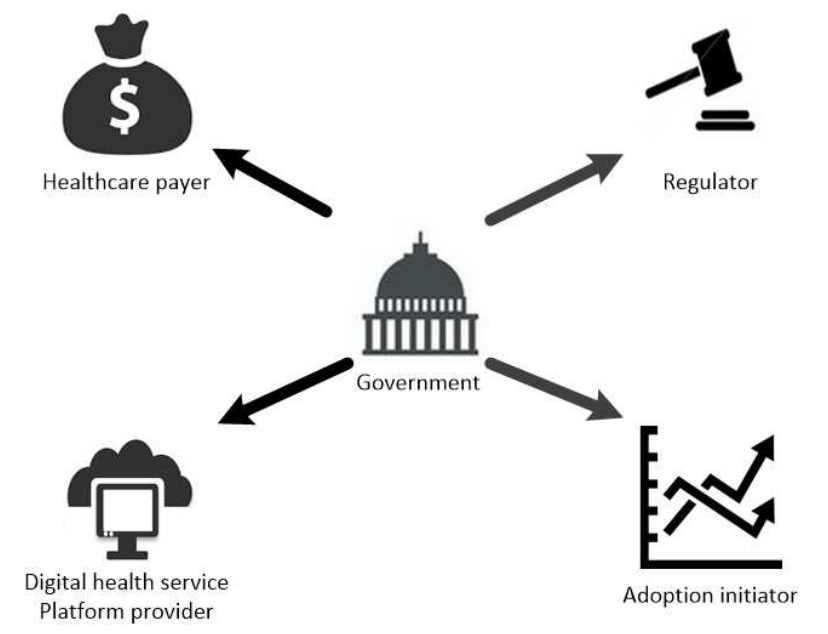

Figure 2. The different roles the government can play simultanosuasly whitin a value network of digital health services.

\section{A. The government as regulator}

Bringing a digital health service to the market requires in most cases a quality label from a regulatory agency (FDA for the U.S., EC for European Countries, Health Canada, etc.). In short, this label indicates that the medical device or software application is safe to use.

The requirement and degree of regulation for a device (depending on the country) can have a serious impact on the value network. For example, not all stores may sell medical devices or for instance when a digital health service is certified, 
it can increase the credibility for the general practitioners or physicians in general, etc. Depending on the intended use of the device or application or the risk it poses to patient, a certain level of certification can be obliged. When it's not obliged, it can be a strategic choice of the developers.

Besides providing quality assuring regulation on the devices or services, the government can impact the value network via legislating (e.g. setting a deadline and forcing EHR-software companies to develop connector modules between the software suites and the national health platform).

\section{B. The government as payer}

In many countries where a public health care system is installed, one of the roles of the government is to act like a healthcare payer (often under the form of national health services or health care insurances paid via taxes). In addition, governmental institutions regulate reimbursement for health care (e.g. health care practices, drugs, medical devices, home care services, etc.).

Obtaining reimbursement for health care requires proof of effectiveness (medical evidence based) and in most cases a more cost-effective outcome than the current alternative (higher incremental effectiveness-cost ratio (ICER)) [14]. Being reimbursed as digital health service is a desired scenario because in that case the WTP- barrier dissolves. But because of the explosive growth of digital health services (e.g. mHealth apps, monitoring devices, etc.) while budgets are limited, it is unlikely that current reimbursing systems will still be sustainable in the near future. On the other hand new reimbursement schemes will evolve.

\section{The government as platform provider}

For already two decades, many national governments of developed countries have been ordering an own online national healthcare platform to stimulate and facilitate sharing healthcare information between the correct actors in a secured way. First goals were: facilitating medical information sharing between hospitals, specialists and general practitioners, now also more patient centered services such as a vaccination journal, care journal and medication scheme are becoming available.

Since these platforms are typically also responsible for official identity authorization and authentication of physicians, many private platforms use extensions of the national platform. Chances are likely that the national healthcare platform is a key-role in the value network of a digital health care service.

\section{The government as adoption initiator}

Adoption of these national platforms were typically slow. Not only because they were hard and cumbersome to use, but mainly because it required a cultural change, being the transition from a complete paper based administration towards a digital one.

Nowadays, adoption for new types of platforms is still slow [13]. Reasons for this phenome can be the extra effort that is needed of the physicians without a being financially compensated for them. In other words, what's in it for them?
This could also indicate that the value added is not attractive enough for these actors. In order to overcome this issue, the government can provide incentives for using the system and sharing information with it. After a period of incentives, they could also penalize ignorant attitude of the users. This is what the Danish government did to boost the adoption of the Dak-e platform (91\% in two years!) (See section III: examples of challenging value networks). The government threatened GPs to cancel their GP license if they wouldn't use the Dak-e platform. So providing the correct incentives and penalizations is a governmental tool to initiate adoption of digital health care services.

\section{CONSIDERATIONS AND GUIDELINES}

Although the importance of the government as actor within the value network can be large (e.g. impact of being reimbursed, importance of new regulations, etc.), a fine balance must be found between the value network dependency of governmental actions or decisions and the potential roles of the government within the value network to fill the existing gaps. In general following guidelines are valid:

First, setting up a business model or value network based on a potential change in regulation can hold a large business potential but also comes with uncertainty. Being able to foresee future adaptions of regulation and react quickly to changes in legislation, will be beneficial.

Second, it's not recommended to develop a value network that is strongly depended on reimbursement schemes if they are currently not installed yet. Though, the importance of chronic care will grow because of the aging population, so it can be expected that specific care pathways and reimbursement structures for certain chronic pathologies will be defined and developed further.

Furthermore, a fair cost allocation for all involved actors is necessity for creating a sustainable value network [7]. An actor who is impacted negatively when digital health services are integrated is likely to block further adoption of the service. Determining a fair cost allocation is challenging because both cost and benefits for each actor should be quantified. The costs can often be quantified straight forward in terms of financial resources and time. The benefits on the other hand have two different components; 1) quantitative benefits (decrease in operational expenditures, less administration, less errors, etc.) and 2) qualitative benefits such as level of anxiety, level of peace of mind, decreased level of social isolation, etc.). Although there exist many tools [15] to quantify qualitative effects, measuring it often requires large trials.

A fair cost/benefit ratio also means that digital health service providers, especially mHealth and eCare services have to be careful when it comes down to involving general practitioners in the value network. Whenever a service needs input from a general practitioner, compensation for this effort proved to be required unless the added value of the service is strong enough.

The challenge of the willingness to pay of the customers of mHealth and eCare services is multi-faceted. Services which will be able to build up medical evidence of their impact 
probably will gain interest of health insurers. Financial intervention of health insurers will dissolve the WTP barrier. For services that have difficulties building up the medical evidence following remarks could be considered; First: the proposed added value is not strong enough since no actor wants to pay for it. Next, rethink the business model and value network, other cost allocation schemes could maybe result in a lowered cost for the end consumer. And finally, in some niche segments of the complete market for digital health services there is willingness to pay for these kind of services (e.g. the success of fitness and (health) tracking mobile applications). Together with the upcoming smartwatches, it can be expected that these niches will expand and impact the overall WTP for digital health services over time.

\section{CONCLUSIONS}

eHealth, mHealth and eCare services (digital health services) are currently entering the market and the healthcare sector in large numbers. Due to still existing barriers overall adoption remains low. Especially defining a sustainable value network between the involved actors is often a hard task. This papers highlights three reasons for the gap in value network configurations: 1) currently low and unclear willingness to pay by service end users, 2) an unbalanced cost/benefit ratio, or unfair cost allocation between the involved actors and 3) a negative impacted business model of one or more actors resulting in a blocked or slowed down adoption of the service. Investigation of three different cases confirms these points of perspective.

Although the role of the government in the value network can have a large impact on the adoption (e.g. reimbursement of the service), their complete potential impact is often not completely considered. Governments can steer, boost or block adoption by one of their following roles: 1) the government as regulator (e.g. providing regulations on service quality and labels, formulating new regulations impacting the business models and cases, etc.), 2) the government as payer (e.g. foreseeing reimbursement for the service), 3) the government as platform provider; many developed countries already have an established national platform for healthcare information sharing and authorization, which can impact the service provision and 4) the government as adoption initiator; by providing incentives or penalizations towards actors, the government can boost or block adoption.

Based on these findings this work provides guidelines and considerations for integrating digital health services into the current care practices.

\section{FUTURE WORK}

Since integrating digital health services often requires a multi-actor value network, determining a fair cost allocation is in many cases challenging. Initial work was done on how to obtain cost/benefit ratios that are acceptable for all actors involved in the value network [7]. Ongoing research focusses on further developing cost allocation methods that balance the cost/benefit ratios for all actors involved and for both quantitative and qualitative impacts, while optimizing the social impact (being cost-effective and qualitative care) of digital health service.

\section{ACKNOWLEDGMENT}

F. Vannieuwenborg has received funding from the Agency for Innovation by Science and Technology in Flanders (IWT) through his PhD grant.

\section{REFERENCES}

[1] Schweitzer, J., and Synowiec, C.: 'The economics of eHealth and mHealth', Journal of health communication, 2012, 17, (sup1), pp. 73-81

[2] Vannieuwenborg, F., Van Ooteghem, J., Verbrugge, S., Colle, D., and Pickavet, M.: 'Smart home care platforms: where is the added value?'. Proc. International Telecommunication Society, Brussels2014 pp. 1-27

[3] Carroll, R., Cnossen, R., Schnell, M., and Simons, D.: 'Continua: An interoperable personal healthcare ecosystem', Pervasive Computing, IEEE, 2007, 6, (4), pp. 90-94

[4] Allee, V.: 'Value network analysis and value conversion of tangible and intangible assets', Journal of Intellectual Capital, 2008, 9, (1), pp. 5-24

[5] Gagnon, M.-P., Ngangue, P., Payne-Gagnon, J., and Desmartis, M.: 'mHealth Adoption by Healthcare Professionals: A Systematic Review', Journal of the American Medical Informatics Association, 2015

[6] Van Ooteghem, J., Ackaert, A., Jacobs, A., Maes, S., and Verhoeve, P.: 'Scaling up the evidence: sustainable models for eHomeCare', eChallenges 2011, 2011

[7] Vannieuwenborg, F., van Ooteghem, J., Vandenberghe, M., Verbrugge, S., Pickavet, M., and Colle, D.: 'A methodology for multi-actor evaluation of the impact of eCare services,'. Proc. SSH: IEEE International Workshop on Service Science for eHealth, Healtcom2013

[8] Familyware. Be Well Point. 2015-06-29. URL:http://familyware.be/products/be-well-point/. Accessed:2015-0629.(Archived by WebCite ${ }^{\circledR}$ at http://www.webcitation.org/6ZdxVrMhS)

[9] Orde van Geneerheren. Pilootproject "Be Well Point" van de firma MSD [Pilot project: "Be Well Point" of a company named MSD]. Nationale Raad. 2015-06-29.

URL:http://ordomedic.be/nl/adviezen/advies/pilootproject-be-wellpoint-van-de-firma-msd. Accessed:2015-06-29.(Archived WebCite $\AA$ at http://www.webcitation.org/6ZdyHi2cR)

[10] Kitsiou, S., Paré, G., and Jaana, M.: 'Effects of Home Telemonitoring Interventions on Patients With Chronic Heart Failure: An Overview of Systematic Reviews', Journal of medical Internet research, 2015, 17, (3)

[11] Orde van Geneerheren. Vergoeding in geval van telemonitoring [Reimbursement for tele monitoring]. Nationale Raad. 2015-06-29.

URL:http://ordomedic.be/nl/adviezen/advies/vergoeding-in-geval-vantelemonitoring. Accessed: 2015-06-29. (Archived by WebCite® at http://www.webcitation.org/6ZdyafGjp)

[12] Danish Quality Unit of General Practice. Sentinel Data Capture. . 201506-29. URL:http://www.dak-e.dk/flx/en/general-practice/. Accessed: 2015-06-29.(Archived by
http://www.webcitation.org/6ZdzM1DMN)

[13] Vlaamse Overheid. Vitalink is het nieuwe, digitale platform van de Vlaamse overheid voor het veilig delen van zorg- en welzijnsgegevens.. 2015-06-29. URL:http://www.vitalink.be/VitaStart.aspx/. Accessed: 2015-06-29. (Archived by http://www.webcitation.org/6ZdyoOK9Z)

[14] Annemans, L.: 'Health economics for non-economists: an introduction to the concepts, methods and pitfalls of health economic evaluations' (Academia Press, 2008. 2008)

[15] Hirani, S.P., Beynon, M., Cartwright, M., Rixon, L., Doll, H., Henderson, C., Bardsley, M., Steventon, A., Knapp, M., and Rogers, A. 'The effect of telecare on the quality of life and psychological wellbeing of elderly recipients of social care over a 12-month period: the Whole Systems Demonstrator cluster randomised trial', Age and ageing, 2014, 43, (3), pp. 334-341 